\title{
Taylor Equation of Durability and Its Modification
}

Karol Vasilko

Faculty of Manufacturing Technologies, Technical University of Košice, Bayerova 1, 08001 Prešov, SR. E-mail: karol.vasilko@tuke.sk

Recent development of the application of new kinds of material in transport and production technology places higher requirements on the technologist at the determination of cutting conditions. The assortment of recent kinds of cutting material enables to intensify cutting conditions while maintaining acceptable tool durability. The dependence of tool durability on cutting speed, or ,basic law of machining“6, is the basic means to determine tool durability at selected cutting conditions. The paper contains a suggestion to modify the original Taylor equation on recent conditions of productive machining.

Keywords: Machining, tool life, tool wear, sintered carbide

\section{References}

[1] TAYLOR, F, W. (1906) On the art of cutting metals. Transaction of the ASME, 28, November 1906, s. 31-279, 281-350

[2] VASILKO, K., MACUROVÁ, A. (2006). Identifikácia rovnice $T=\mathrm{f}\left(v_{\mathrm{c}}\right)$ pre spekaný karbid Technologické inžinierstvo, III, č.2/2006, s.8-11

[3] BOBROV, V.F., et all. (1967). Razvitije nauki o rezanii metallov. Moskva: Mašinostrojenije, 1967, 414

[4] BUDA, J., BÉKÉS, J. (1967). Teoretické základy obrábania kovov. Bratislava: ALFA, 1967, $698 \mathrm{s.}$

[5] GRANOVSKIJ, G. I., GRANOVSKIJ, V. G. (1985). Rezanije metallov. Moskva: vyššaja škola 1985, 304 s.

[6] GRZESIK, W. (1998). Podstawy skawania materialow metalowych. Warszawa: Wydawnictwa Naukowo-Techniczne, 1998, 380 s.,ISBN 83-204-2311-2

[7] KALPAKJIAN, S. (1999). Manufacturing engineering and technology. New York: Addison Wesley Publishing Company, 1989, pp.1999, ISBN 0-201-12849-7

[8] KOVAČ, P., MILIČIČ D. Rezanje metala Novi Sad: Univerzitet u Novom Sadu, 240 s., ISBN 86.899-0015-1

[9] MÁDL, J., KVASNIČKA, J. (1998). Optimalizace obráběcího procesu. Praha: Vydavatelství ČVUT, 1998,168 S.

[10] PŘIKRYL, Z., MUSÍLKOVÁ, R. (1982). Teorie obrábění. Praha: SNTL, 1982, 235 s.

[11] SMART, E. F., TRENT, E. M. (1985). Distribution des temperatures dans les outils de couple utilizes pour 1' usinage du far, du titane et du nickel. Bull. Cerlce étud. Métaux, 1985, num. spac., 443-447. Discuss., 478-479.

[12] WEBER, H., LOLADZE, T.N. (1986). Grundlagen des Spanens. Berlin: VEB Verlag Technik, 1986, 255 s.

[13] MÜLLER, M., VALÁŠEK, P. (2012). Abrasive wear effect on Polyethylene. Polyamide 6 and polymeric particle composites. Manufacturing Technology, 2012, Vol 12, No.12

[14] MRKVICA, I. et al. (2012). Cutting ceramic by turning of nickel alloy Onconel. Manufacturing Technology, Vol. 12, No. 13, 2012, pp. 178-186, ISSN 1213-2489

[15] KOCMAN, K., PROKOP, J. (2008). Cutting Tools for Material Turning. Manufacturing Technology, 2008, Vol. IV, p. 5-10, ISSN 1213-2489 